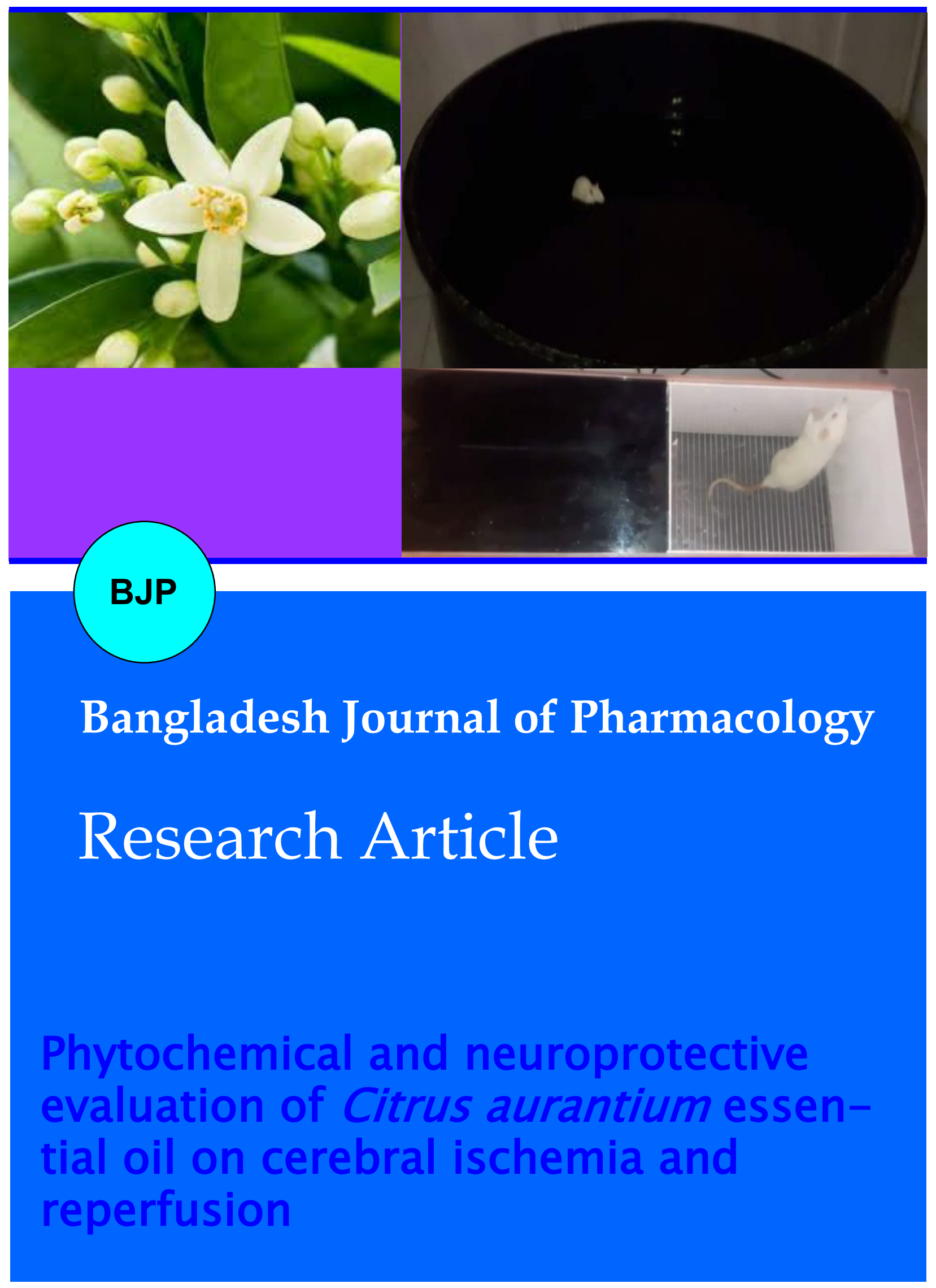




\title{
Phytochemical and neuroprotective evaluation of Citrus aurantium essential oil on cerebral ischemia and reperfusion
}

\author{
Arezo Sadeghimanesh', Valiallah Khalaji-Pirbalouty' ${ }^{1}$, Zahra Lorigooini' ${ }^{2}$, Mahmoud \\ Rafieian-Kopaei ${ }^{2}$, Akram Torki ${ }^{1}$ and Zahra Rabiei ${ }^{2}$ \\ ${ }^{1}$ Department of Biology, Faculty of Science, Shahrekord University, Shahrekord, Iran; ${ }^{2}$ Medicinal Plants Research \\ Center, Basic Health Sciences Institute, Shahrekord University of Medical Sciences, Shahrekord, Iran.
}

\begin{tabular}{|lr|}
\hline \multicolumn{2}{|l|}{ Article Infor } \\
\hline Received: $\quad$ 13 July 2018 \\
Accepted: $\quad$ 3 November 2018 \\
Available Online: $\quad 7$ December 2018 \\
DOI: 10.3329/bjp.v13i4.37408 \\
\\
\\
\\
\\
Cite this article: \\
Sadeghimanesh A, Khalaji-Pirbalouty \\
V, Lorigooini Z, Rafieian-Kopaei M, \\
Torki A, Rabiei Z. Phytochemical and \\
neuroprotective evaluation of Citrus \\
aurantium essential oil on cerebral \\
ischemia and reperfusion. Bangladesh \\
J Pharmacol. 2018; 13: 353-61.
\end{tabular}

\begin{abstract}
This study was conducted to investigate the neuroprotective effect of Citrus aurantium essential oil on hippocampal injury induced by transient global cerebral ischemia and reperfusion in rat. In total 50 rats were randomly assigned into five groups; control, sham, ischemia, and essential oil-treated ( 50 or $75 \mathrm{mg} / \mathrm{kg}$ ) rats. Ischemia was induced by occlusion of the carotid artery for $30 \mathrm{~min}$. Spatial memory, passive avoidance learning, anti-oxidant capacity, and lipid peroxidation during ischemia/reperfusion were evaluated. The compounds of the essential oil were analyzed by gas chromatography/mass spectrometry. Induction of ischemia/reperfusion caused a decline in learning and passive avoidance memory in rats. C. aurantium exerted protective effects on the spatial memory, passive avoidance learning, anti-oxidant capacity, and lipid peroxidation during ischemia/reperfusion in animals. The main compounds of the essential oil were camphor $(45.9 \%)$, thymol $(11.2 \%)$, linalool $(6.6 \%)$, carvacrol $(6.3 \%)$ and borneol $(2.9 \%)$. The essential oil with anti-oxidant compounds significantly decreased the symptoms of ischemia/reperfusion injury.
\end{abstract}

\section{Introduction}

Cerebral ischemia refers to reduction of brain blood supply which leads to reduced brain oxygen or cerebral hypoxia resulting in stroke or death of the brain tissue (Nussmeier, 2002). Atherosclerosis, blood clot, embolism, vessels contraction, hypotension, suffocation and tachycardia are predisposing factors for the ischemia (Hadjinikolaou et al., 2004). Reperfusion usually causes more severe tissue damage. While a sharp reduction or temporary interruption of blood flow in an area of the brain causes ischemia and after a short time, the cells in the central region (core) are destroyed, but the surrounding cells in the penumbra survive for a longer time due to receiving the blood from the surrounding regions (Adams et al., 1993; Hossmann, 1994). Ischemia causes decline in transfer of oxygen and nutrients to tissues and consequently dysfunction of the respective organs (Aazami, 2004). Moreover, decreased cell oxygen concentration causes decrease in adenosine triphosphate (ATP). In such condition, the cell uses anaerobic respiration to produce ATP for survival, which causes lactate accumulation and then acidosis and cell death (Pham-Huy et al., 2008; Wells et al., 2010).

Free radicals have unpaired electrons that can induce damage to many biomolecules such as nucleic acids, proteins, and lipids and disturb the structure and function of these molecules (Bakhtiaria et al., 2017; Niki et al., 1995). Malondialdehyde is one of the most important final products of reactions of free radicals and one of the products of lipids oxidation (Nakai et al., 2000). Nature neutralizes these invasive agents through 
developing anti-oxidant processes. Generally, antioxidants prevent the formation of free radicals such as reactive oxygen species (ROS) or scavenge them. These agents reduce the lipid peroxidation and damage to DNA. Normally, there is a balance between production of free radicals and anti-oxidant defense system, but if this condition is disturbed for any reason, a condition called oxidative stress occurs (Bir et al., 2006; Faraji et al., 2008).

The hippocampus is a structure on the floor of the lateral ventricle in the temporal lobe in the brain (Meilandt et al., 2004). This structure plays a fundamental role in consolidating memory and spatial learning in the mammals (Hritcu et al., 2017), and is highly susceptible to ischemia and hypoxia (Meilandt et al., 2004).

Actually, due to the multifarious pathological process of ischemia, using a synthetic and single therapy does not seem effective and hence researches for seeking potent lead compounds is rising. Furthermore, it has been increased more consideration to medicinal plants and their active components as active source in the management of ischemia (Jamshidi-Kia et al., 2018).

Citrus aurantium L. is one of the highly consumed and native medicinal plants of Iran that is called sour orange (Huang et al., 1995). It has several properties in Iranian traditional medicine such as gastric secretionlowering, anti-bleeding, anti-bile and sedative activities. The flowers of this plant are used to treat neurological disorders such as hysteria, seizure and anxiety (Mahmoudi et al., 2005; Chutia et al., 2008; Espina et al., 2010). Given the anti-oxidant properties of C. aurantium, we conducted this study to investigate the neuroprotective effect of $C$. aurantium essential oil on damage induced by transient global cerebral ischemia and reperfusion in Wistar rats.

\section{Materials and Methods \\ Extraction of essential oils}

C. aurantium flowers were collected and botanically authenticated by a botanist (Dr. Hamze-ali Shirmardi) and deposited a specimen in the Herbarium unit of Medical Plants Research Center, Shahrekord University Medical Sciences, Shahrekord, Iran (Herbarium no. 324). Powdered flower was distilled in water using a Clevenger-type apparatus. The extraction was conducted for 4 hours and then the essential oil collected and dehydrated using water-free sodium sulfate. The prepared essential oil was stored at $-20^{\circ} \mathrm{C}$ until injection to the gas chromatography/mass spectrometry.

\section{Analysis of essential oil}

Gas chromatography/mass spectrometry analysis of the oil was performed on a ThermoQuest-Finnigan chromatograph; model TRACE MS using a capillary column (DB-5, $30 \mathrm{~m} \times 0.25 \mathrm{~mm})$. Split ratio was 1/100 and the flow rate for the helium carrier gas $(99.999 \%)$ was $1.1 \mathrm{~mL} / \mathrm{min}$; injector temperature, $250^{\circ} \mathrm{C}$. The sample $(0.2 \mu \mathrm{L})$ was injected under split condition, ionization energy, $70 \mathrm{Ev}$. The temperature program was $60-250^{\circ} \mathrm{C}$ at a rate of $5^{\circ} \mathrm{C} / \mathrm{min}$; the column used and other operating conditions were the same as those of gas chromatography; transfer-line temperature was $250^{\circ} \mathrm{C}$. n-Alkanes were used to calculate the Kovat's Indices (KI) for the detected compounds. Tentative identification of the compounds was based on the comparison of their relative retention time and mass spectra with those from Wiley 275 and Adams data libraries for Gas chromatography/mass spectrometry (Adams and Sparkman, 2007).

\section{Determining the anti-oxidant capacity of essential oil}

After preparing the essential oil stock and DPPH $(2,2-$ diphenyl-1-picrylhydrazyl), the samples were incubated in the dark for 15 min and the samples' absorbance was read at $517 \mathrm{~nm}$. Ethanol was used as blank and DPPH used as control. After calculating the inhibition rate of free radicals by the essential oil, anti-oxidant activity was reported as $\mathrm{IC}_{50}$ (Pourmorad et al., 2006).

\section{Animals}

Fifty male adult Wistar rats weighing 250-300 g were kept at $21 \pm 2{ }^{\circ} \mathrm{C}$ temperature, under 12 hours dark/ light cycle with free access to the same food and water were used. The rats were assigned to 5 groups: Group 1: Control group that underwent no surgery and were administered with distilled water alone; Group 2: Sham group that underwent surgery without drug administration and were administered distilled water alone; Group 3: Ischemia group that underwent ischemia without drug administration and were administered distilled water alone; Groups 4 and 5 received C. aurantium essential oil (50 and $75 \mathrm{mg} / \mathrm{kg}$, respectively) and were induced ischemia. The essential oil was administered intraperitoneally.

\section{Induction of ischemia}

After induction of anesthesia using $400 \mathrm{mg} / \mathrm{kg}$ of chloral hydrate, anterior lateral region of the neck underwent surgery after carotid sheath was determined, and common carotid arteries were accurately identified and separated from the vagosympathetic nerve. Then, carotid arteries were occluded for $30 \mathrm{~min}$. Behavioral tests were conducted one week after the induction of ischemia. At completion of the behavioral tests, the heart blood samples were collected. Finally, hippocampus, cortex, and subcortex were taken out from the brain, separated on the ice and used for biochemical analyses. The blood samples were centrifuged and the serum isolated and used for the biochemical analyses. 


\section{Water maze test}

To conduct the water maze test, each rat was given a 60 sec to find the platform. If they could not find the platform, they were guided to it by the researcher. Between each two trials, the rats were given a $30 \mathrm{sec}$ opportunity to rest so that they could examine the surrounding. Between two blocks, the rats were taken out from water for $10 \mathrm{~min}$ to rest in the cage. Each rat was trained for four days, four times per day, and the test was repeated on day 5 without the platform that was considered probe day (Quervain et al., 1998).

\section{Anti-oxidant capacity of the serum and brain}

To measure the anti-oxidant capacity of serum and brain, three solutions were used consisting of buffer (1.55 mL sodium acetate, $8 \mathrm{~mL}$ concentrated acetic acid reaching $500 \mathrm{~mL}$ by adding distilled water), ferrous chloride solution $\left[270 \mathrm{mg} \mathrm{FeCl}{ }_{3}\left(6 \mathrm{H}_{2} \mathrm{O}\right)\right.$ reaching $50 \mathrm{~mL}$ by adding distilled water] and triazine solution (47 $\mathrm{mg}$ triazine solved in $40 \mathrm{~mL}$ of $40 \mathrm{mM} \mathrm{HCl}$ ). The labor solution was prepared by addition of $10 \mathrm{~mL}$ of the first solution, $1 \mathrm{~mL}$ of the second solution, and $1 \mathrm{~mL}$ of the third solution. $25 \mu \mathrm{L}$ of the serum sample and $25 \mu \mathrm{L}$ of the homogenized brain sample were added to $1.5 \mathrm{~mL}$ of the labor solution and then kept at $37^{\circ} \mathrm{C}$. Optical

\section{Box 1: Shuttle Box Test}

\section{Principle}

The shuttle box provides an environment to carry out the conditioned reflexes (active and passive avoidance) in two steps: learning and memory test.

\section{Requirements}

Computer; Rat; Shuttle box (Borj-Sanat Azma, Iran); Software; Stimulator (ST-5500)

\section{Component}

The shuttle box consists of two equally sized illuminated and dark compartments $(20 \times 80 \times 20 \mathrm{~cm})$ with two independent grid floors. The floor of the dark compartment had a stainless steel shock grid floor. The electric shock was delivered to the grid floor with a stimulator $(50 \mathrm{~Hz}, 1 \mathrm{~mA}$ for $1 \mathrm{sec})$. These two compartments were separated by a guillotine door $(7 \times 9 \mathrm{~cm})$ that could be raised to $10 \mathrm{~cm}$. A door at the top allows an easy access of the rat to inside the box. The cage contains a general sound generator and a visual stimulus (light) for each compartment.

\section{Procedure}

Day 1

Each rat was placed in the instrument to accustom it

Day 2

Each rat was placed in the instrument to accustom it

Day 3

A test of acquisition was conducted. absorbance was read at $593 \mathrm{~nm}$ wavelength (Benzie et al., 1999).

\section{Serum and brain malondialdehyde levels}

To measure the amount of the serum malondialdehyde, thiobarbituric acid ( $0.5 \mathrm{~g})$ was mixed with acetic acid $(20 \%, 80 \mathrm{~mL})$ and then the $\mathrm{pH}$ was set at 3.5 using $\mathrm{NaOH}$ and its volume reached $100 \mathrm{~mL}$ by adding acetic acid $(20 \%)$. The serum sample $(100 \mu \mathrm{L})$ was mixed with SDS $(8.1 \%, 100 \mu \mathrm{L})$ and the labor solution $(2.5 \mathrm{~mL})$. The samples were placed in a bain-marie for $60 \mathrm{~min}$ and then cooled and centrifuged at 4,000 rpm. The optical absorbance of the supernatant was recorded at $523 \mathrm{~nm}$ wavelength.

To measure the brain malondialdehyde, the brain tissue $(1 \mathrm{~g})$ in cooled KCL $(2.5 \%)$ was homogenized at $10 \%$ (weight-volume) proportion, and then incubated in a metabolic shaker at $37 \pm 1^{\circ} \mathrm{C}$ for $60 \mathrm{~min}$. Then, tetrachloroacetic acid $(5 \%, 1 \mathrm{~mL})$ and thiobarbituric acid $(67 \%, 1 \mathrm{~mL})$ were added to it and mixed well after each step. The content of each vial was transferred to the centrifugation tube and centrifuged at 2,000 rpm for 15 min. Then, the supernatant was transferred to another tube and placed in bain-marie. After $10 \mathrm{~min}$, the tubes were cooled and the absorbance was read at $535 \mathrm{~nm}$

Step 1: The rat was separately placed into the illuminated compartment

Step 2: After a period of acculturation (for $2 \mathrm{~min}$ ), the guillotine door was opened. Upon entry into the dark compartment, the door was closed

Step 3: An electrical shock was exerted on the rat such that it just paddled.

Step 4: The rat was returned to its home cage after $20 \mathrm{sec}$

Step 5: The rat was again placed into the illuminated compartment after $2 \mathrm{~min}$

Step 6: The delay in entering the dark compartment was recorded

Comment: If the rat did not enter the dark compartment within $2 \mathrm{~min}$, successful acquisition of passive avoidance response would be recorded

Day 4

Step 1: The same test in similar manner was carried out on each rat without stimulation. The delay in entering the dark compartment was recorded to a maximum of $5 \mathrm{~min}$.

Comment: Short latencies mean poor retention compared to the significant longer latencies.

\section{Advantage}

The shuttle box can be easily set up and dismantled.

\section{References}

Khalili et al., 2009; Hosseinzadeh et al., 2013 
Table I

Chemical composition of $C$. aurantium essential oil

\begin{tabular}{|c|c|c|c|c|}
\hline No. & Compound & Rt & $\mathrm{RI}^{\mathrm{a}}$ & $\begin{array}{l}\text { Area } \% \\
\text { GCMS }\end{array}$ \\
\hline 1 & Benzaldehyde & 4.6 & 961.1 & 0.7 \\
\hline 2 & p-Cymene & 5.8 & 1022.1 & 0.4 \\
\hline 3 & Limonene & 5.8 & 1025.7 & 1.2 \\
\hline 4 & 1,8-Cineole & 5.9 & 1028.4 & 1.3 \\
\hline 5 & $\begin{array}{l}\text { Benzene acetalde- } \\
\text { hyde }\end{array}$ & 6.2 & 1042.3 & 2.2 \\
\hline 6 & $\gamma$-Terpinene & 6.5 & 1055.4 & 0.2 \\
\hline 7 & Unknown & 6.9 & 1072.1 & 1.1 \\
\hline 8 & trans-Linalool oxide & 7.2 & 1086.5 & 0.5 \\
\hline 9 & Linalool & 7.4 & 1097.3 & 6.6 \\
\hline 10 & Hotrienol & 7.5 & 1102.5 & 0.05 \\
\hline 11 & trans-Pinocarveol & 8.4 & 1140.5 & 0.5 \\
\hline 12 & Camphor & 8.6 & 1145.1 & 45.9 \\
\hline 13 & Citronellal & 8.7 & 1151.1 & 0.4 \\
\hline 14 & Borneol & 9.1 & 1168.4 & 2.9 \\
\hline 15 & Terpinen-4-ol & 9.4 & 1179.7 & 0.5 \\
\hline 16 & p-Cymen-8-ol & 9.6 & 1190.3 & 0.7 \\
\hline 17 & a-Terpineol & 9.7 & 1194.5 & 0.6 \\
\hline 18 & Myrtenal & 9.9 & 1200.7 & 0.2 \\
\hline 19 & Myrtenol & 9.9 & 1203 & 0.3 \\
\hline 20 & trans-Carveol & 10.5 & 1223.6 & 0.4 \\
\hline 21 & Pulegone & 11.0 & 1241.3 & 0.1 \\
\hline 22 & Cuminic aldehyde & 11 & 1242.4 & 0.1 \\
\hline 23 & Carvone & 11.1 & 1245.4 & 0.4 \\
\hline 24 & Thymol & 12.4 & 1294.1 & 11.2 \\
\hline 25 & Carvacrol & 12.7 & 1304.3 & 6.3 \\
\hline 26 & Piperitenone & 13.6 & 1342.3 & 0.4 \\
\hline 27 & Piperitenone oxide & 14.2 & 1365.6 & 2.9 \\
\hline 28 & trans-Caryophyllene & 15.5 & 1418 & 0.3 \\
\hline 29 & $\beta$-Selinene & 17.2 & 1484.9 & 0.6 \\
\hline 30 & Bisabolene<beta-> & 17.7 & 1505.2 & 0.3 \\
\hline 31 & $\begin{array}{l}\text { 2,5-Di-tert- } \\
\text { butylphenol }\end{array}$ & 17.8 & 1511.2 & 0.3 \\
\hline 32 & Nerolidol<E-> & 19.0 & 1560.9 & 0.5 \\
\hline 33 & Spathulenol & 19.4 & 1577.7 & 0.4 \\
\hline 34 & Caryophyllene oxide & 19.5 & 1582.4 & 0.9 \\
\hline 35 & Globulol & 19.5 & 1585 & 1.6 \\
\hline 36 & Viridiflorol & 19.7 & 1591.8 & 0.3 \\
\hline 37 & $\beta$-Eudesmol & 21.0 & 1650.9 & 1.8 \\
\hline 38 & $\begin{array}{l}\text { Bisabolol oxide B } \\
\text { <alpha-> }\end{array}$ & 21.1 & 1655.4 & 0.2 \\
\hline 39 & n-Heptadecane & 21.9 & 1688.4 & 2 \\
\hline 40 & n-Octadecane & 24.0 & 1797.5 & 0.6 \\
\hline 41 & n-Nonadecane & 26.1 & 1898 & 0.6 \\
\hline 42 & Dibutyl phthalate & 27.4 & 1966.3 & 0.5 \\
\hline 43 & n-Eicosane & 28.0 & 1999 & 0.4 \\
\hline 44 & n-Heneicosane & 29.9 & 2100.6 & 0.6 \\
\hline 45 & n-Docosane & 31.7 & 2198.9 & 0.2 \\
\hline 46 & n-Tricosane & 33.4 & 2297.7 & 0.3 \\
\hline
\end{tabular}

wavelength (Karatas et al., 2002).

\section{Data analysis}

The data were expressed as mean \pm SEM and analyzed by one-way ANOVA and Tukey's post-hoc test in Excel and SPSS 20 software. The inter-group differences were considered significant if $\mathrm{p}<0.05$.

\section{Results}

\section{Essential oil analysis}

Based on gas chromatography/mass spectrometry analysis, 46 compounds were identified in the C. aurantium essential oil comprising $98.9 \%$ of the whole compounds of the essential oil (Figure 1). The main compounds of the essential oil were camphor $(45.9 \%)$, thymol $(11.2 \%)$, linalool $(6.6 \%)$, carvacrol $(6.3 \%)$ and borneol $(2.9 \%)$ as shown in Table I.

\section{Effect on learning and spatial memory in Morris water maze test}

The findings of Morris water maze test demonstrated that latency to find the platform on day 3 was higher in the ischemic group compared to other groups, and the control group displayed the shortest latency. Intraperitoneal administration with 50 and $75 \mathrm{mg} / \mathrm{kg}$ of the essential oil caused a significant decrease in the latency to find the platform compared to the ischemia group $(p<0.001)$. There was no significant difference in the latency time among the control, sham, and the essential oil $(50$ and $75 \mathrm{mg} / \mathrm{kg}$ ) groups $(\mathrm{p}>0.05)$. There was no significant difference between the two essential oil (50 and $75 \mathrm{mg} / \mathrm{kg}$ ) treated groups ( $>0.05)$ (Figure 2).

Latency to find the platform on day 4 was higher in the ischemia group compared to other groups, and the control group displayed the shortest latency. Intraperitoneal administration with 50 and $75 \mathrm{mg} / \mathrm{kg}$ of the essential oil caused a significant decrease in the latency to find the platform compared to the ischemia group $(\mathrm{p}<0.001)$. There was no significant difference in the latency time among the control and the essential oil $(50 \mathrm{mg} / \mathrm{kg})$ groups $(\mathrm{p}>0.05)$. There was a significant difference between the two essential oil (50 and $75 \mathrm{mg} /$ $\mathrm{kg}$ ) treated groups $(\mathrm{p}<0.01)$ (Figure 2).

Duration of swimming in target zone on the probe day was higher in the control group than other groups, and in the ischemia group, this duration was shorter than that in other groups. Intraperitoneal administration with 50 and $75 \mathrm{mg} / \mathrm{kg}$ of the essential oil caused a significant increase in the duration of swimming in target zone compared to the ischemia group $(p<0.001)$. There was no significant difference in the duration of swimming in target zone among the control, sham, and the essential oil $(50 \mathrm{mg} / \mathrm{kg})$ groups $(\mathrm{p}>0.05)$. There was 


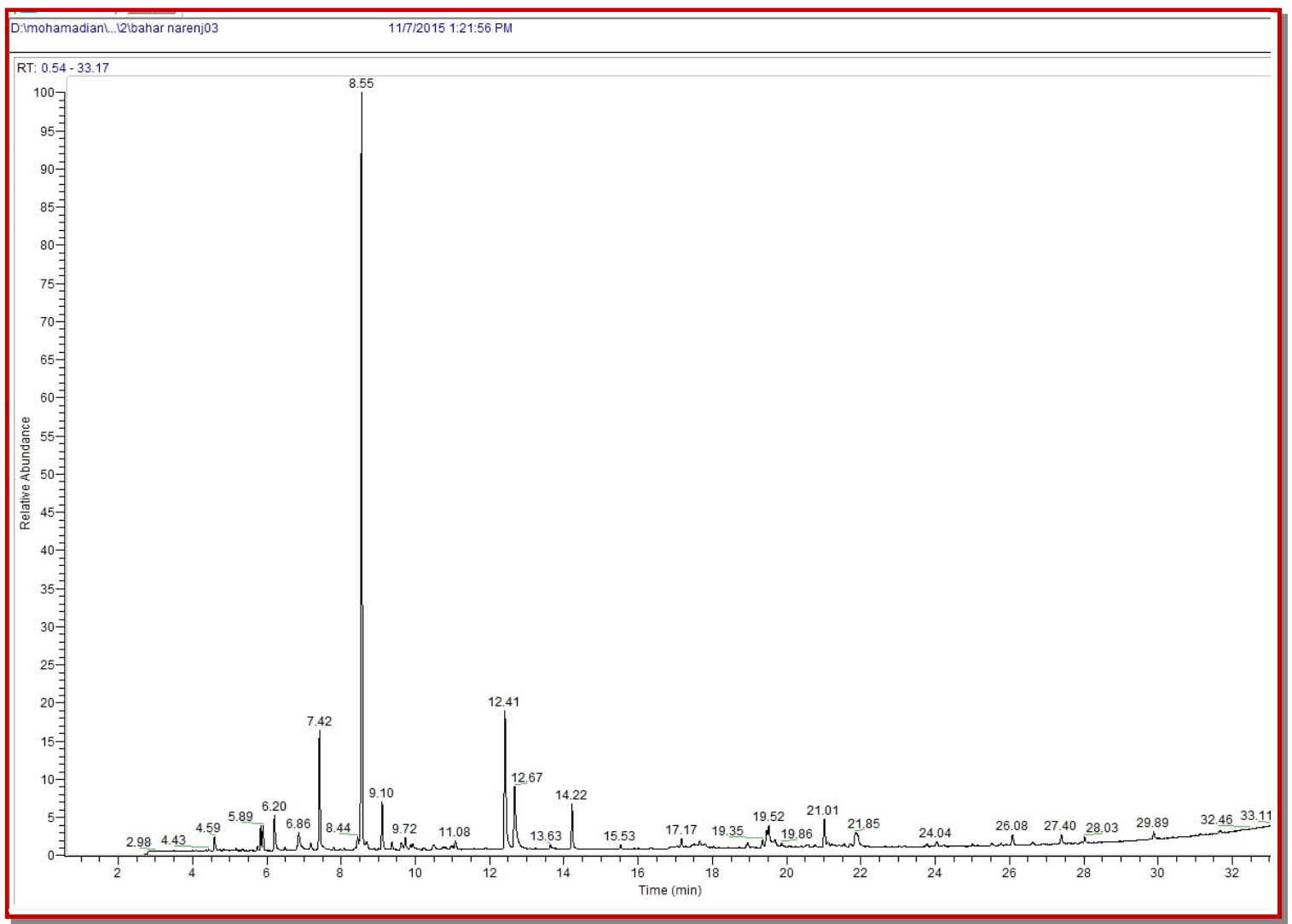

Figure 1: Chromatographic spectrum of C. aurantium essential oil

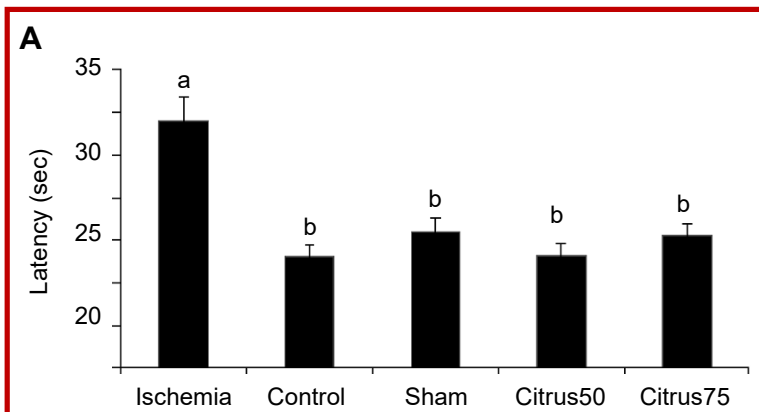

B

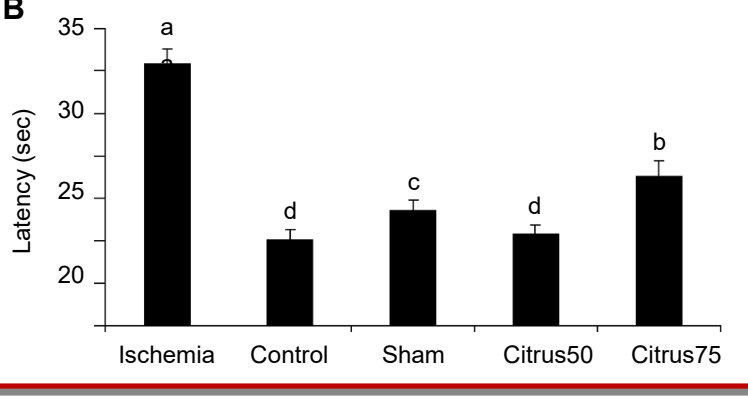

Figure 2: Comparison of the latency to find the platform on day 3 (A) and day 4 (B) between ischemia group and other groups. Similar letters represent no significant difference and dissimilar letters represent significant difference $(\mathrm{p}<0.05)$ (Citrus75 and Citrus50: treated with 75 and $50 \mathrm{mg} /$ $\mathrm{kg}$ of $C$. aurantium essential oil, respectively) a significant difference between the two essential oil (50 and $75 \mathrm{mg} / \mathrm{kg}$ )-treated groups $(\mathrm{p}<0.01)$ (Figure 3).

\section{Effect on passive avoidance memory in shuttle box test}

The time difference between the primary and secondary latency was highly marked in the control group. This difference in the ischemia group was slight. In the essential oil-treated groups, the time difference decreased with increase in the essential oil dose. The secondary latency was higher in the control group than other groups and lowest in the ischemia group. Intraperitoneal administration with 50 and $75 \mathrm{mg} / \mathrm{kg}$ caused a significant increase in the secondary latency compared to the ischemia group $(\mathrm{p}<0.001)$. There was no significant difference in the secondary latency among the control, sham, and the essential oil (50 and $75 \mathrm{mg} / \mathrm{kg}$ ) groups $(\mathrm{p}>0.05)$. There was no significant difference between the two essential oil (50 and $75 \mathrm{mg} /$ $\mathrm{kg}$ ) treated groups ( $>0.05)$, as well (Figure 3).

\section{Effect on anti-oxidant capacity of serum and brain}

The findings demonstrated that the anti-oxidant capacity of the serum was significantly higher in the rats treated with 50 and $75 \mathrm{mg} / \mathrm{kg}$ of the C. aurantium essential oil than in the ischemia group $(\mathrm{p}<0.001$ and $\mathrm{p}<0.05$, respectively). Moreover, the anti-oxidant capacity of the brain was significantly higher in rats 


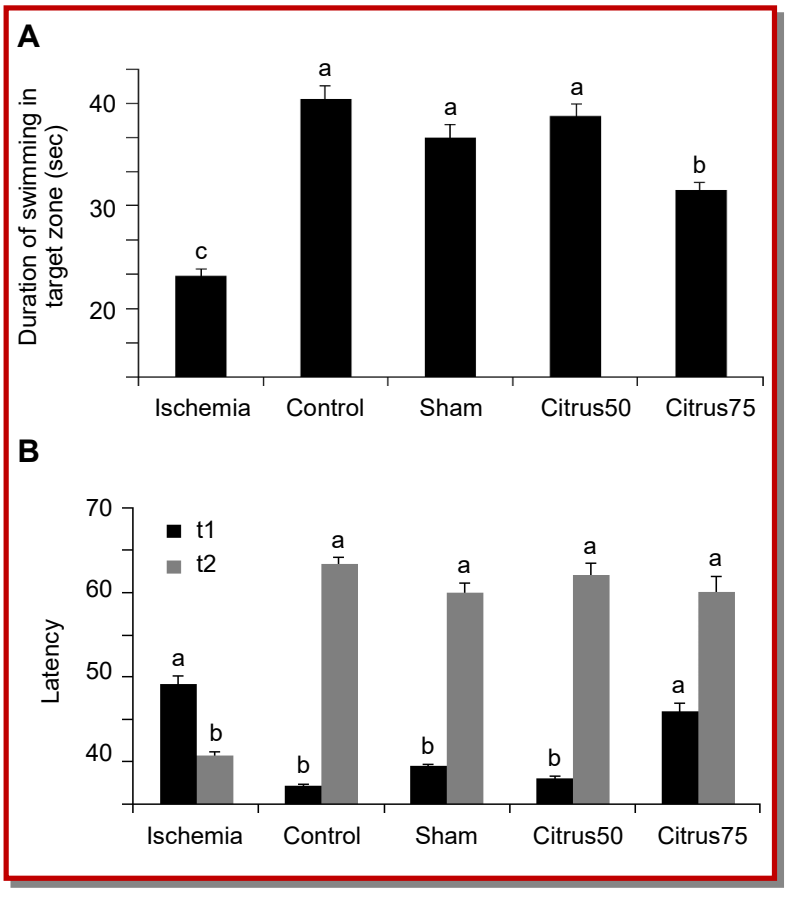

Figure 3: Comparison of the probe day, duration of swimming in target zone (A); Comparison of primary and secondary latency (B) in different groups. Similar letters represent no significant difference and dissimilar letters represent significant difference $(\mathrm{p}<0.05)$ (Citrus75 and Citrus50: treated with 75 and $50 \mathrm{mg} / \mathrm{kg}$ of C. aurantium essential oil, respectively)

treated with 50 and $75 \mathrm{mg} / \mathrm{kg}$ of the C. aurantium essential oil than in the ischemia group $(p<0.001)$. The anti-oxidant capacity of the serum as well as brain was not significantly different between the control, sham and the essential oil $(50 \mathrm{mg} / \mathrm{kg})$ groups $(\mathrm{p}>0.05)$. There was a significant difference between the two essential oil treated groups $(\mathrm{p}<0.001)$ (Figure 4$)$.

\section{Effect on malondialdehyde of serum and brain}

The findings demonstrated that the serum malondialdehyde level was significantly lower in rats treated with 50 and $75 \mathrm{mg} / \mathrm{kg}$ of the C. aurantium essential oil

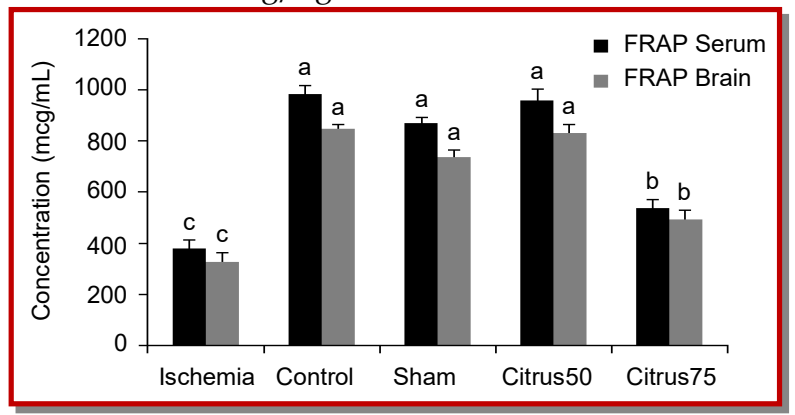

Figure 4: Comparison of anti-oxidant capacity of the serum and brain, similar letters represent no significant difference and dissimilar letters represent significant difference $(\mathrm{p}<0.05)$ (Citrus75 and Citrus50: treated with 75 and $50 \mathrm{mg} / \mathrm{kg}$ of essential oil, respectively)

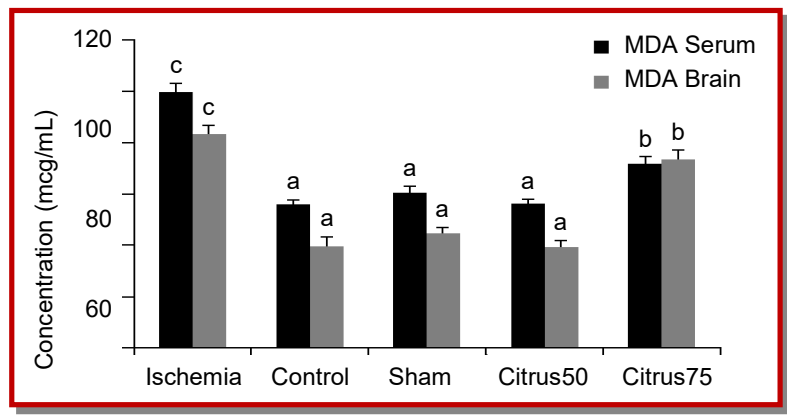

Figure 5: Comparison of the serum and brain MDA level, Similar letters represent no significant difference and dissimilar letters represent significant difference $(p<0.05)$ (Citrus75 and Citrus50: treated with 75 and $50 \mathrm{mg} / \mathrm{kg}$ of essential oil, respectively)

than in the ischemia group $(\mathrm{p}<0.001)$. Moreover, the brain malondialdehyde level was significantly lower in the rats treated with $50 \mathrm{mg} / \mathrm{kg}$ of the C. aurantium essential oil than in the ischemia group $(\mathrm{p}<0.001)$. The brain malondialdehyde level was not significantly different between the ischemia and essential oil $(75 \mathrm{mg} /$ $\mathrm{kg})$ groups $(\mathrm{p}>0.05)$. The serum and brain malondialdehyde levels were not significantly different between the control, sham and the essential oil $(50 \mathrm{mg} / \mathrm{kg})$ groups $(p>0.05)$. There was a significant difference between the two essential oil ( 50 and $75 \mathrm{mg} / \mathrm{kg}$ ) treated groups $(\mathrm{p}<0.001)$ (Figure 5).

\section{Discussion}

In the present study, the findings on anti-oxidant capacity of the serum and brain decreased in the ischemia group compared to the control group. The brain and serum anti-oxidant capacity increased in $C$. aurantium-treated groups compared to the ischemia group. This finding represents the enhanced antioxidant capacity of the serum after administration with the $C$. aurantium essential oil.

Increased levels of malondialdehyde due to lipid peroxidation induced by release of free radicals occur after ischemic/reperfusion injury. Therefore, it seems that the effects of $C$. aurantium essential oil in inhibiting lipid peroxidation and possibly its anti-ischemia effects are due to the presence of anti-oxidant and free radicalinhibiting compounds. The results of malondialdehyde level of the brain and serum in the current study demonstrated that these variables increased in the ischemia group compared to the control group. Moreover, the serum and brain malondialdehyde levels decreased considerably in C. aurantium treated groups compared to the ischemia group which indicates the protective effects of the essential oil compounds in decreasing lipid peroxidation. Therefore, it seems that the decrease in malondialdehyde levels through $C$. aurantium essential oil is associated with the anti- 
oxidant capacity of this plant. Moreover, C. aurantium essential oil anti-oxidant capacity could be attributed to presence of the main compounds of C. aurantium essential oil.

The percentage of the isolated compounds from $C$. aurantium essential oil by gas chromatography/mass spectrometry in this study was $2.9 \%$ for borneol, $6.3 \%$ for carvacrol, $6.6 \%$ for linalool, $11.2 \%$ for thymol, and $45.9 \%$ for camphor. Espina et al. (2010) reported the percentage of linalool $0.47 \%$, thymol $0.12 \%$, and carvacrol $0.10 \%$. Chutia et al. (2008) study demonstrated that linalool to comprise $0.7 \%$ of C. aurantium essential oil, and Hosni et al. (2010) study found borneol to comprise $0.01 \pm 0.01 \%$ and linalool $0.17 \pm 0.06 \%$ (Espina et al., 2010; Chutia et al., 2008; Hosni et al., 2010). The inconsistency in the findings on the chemical compounds of the essential oil in different studies can be related to differences in the weather conditions, the method and duration of isolation of the essential oil, the season of harvest, geographical region, and growth of different parts of the plant (Aminzadeh et al., 2010).

Carvacrol has different biological activities as a main compound of this essential oil. Suo et al. (2014) study demonstrated that carvacrol prevented liver ischemia through its anti-oxidant activity via P13K-Akt signaling pathway by decreasing malondialdehyde and ROS level. In addition, carvacrol increases the activities of catalase, superoxide dismutase, and glutathione oxidase. Carvacrol also increases the P-Akt level and exerts protective effects on the brain ischemic injury, and can easily pass through the blood-brain barrier because of having a low molecular weight. Through increasing Bax/BCL-2 ratio, carvacrol can exert antiapoptotic property and can protect brain ischemia through inhibiting TRPm7 (Suo et al., 2014). Another study showed that thymol could exert anti-inflammatory property through decreasing the levels of inflammatory factors such as troponin1, hsCRP, TBARS, and ST-segments as well as decreasing TNF-a, IL-6, and IL-1 $\beta$ (Meeran et al., 2015).

The results of Morris water maze test in this study demonstrated that in the ischemia group, the latency to find the platform on days 3 and 4 was much higher than that in the control group. This time decreased in the essential oil treated groups compared to the ischemia group. Moreover, the results of this test on the probe day demonstrated that the duration of swimming in the target zone was much lower in the ischemia group compared to the control group, and increased in the essential oil treated groups compared to the ischemia group. This finding represents that spatial memory and learning of the place of the platform enhanced in the essential oil-treated groups.

The results of shuttle box test in the present study demonstrated that the difference between $t_{1}$ and $t_{2}$ was slight in the ischemia group which represents decrease in passive avoidance memory due to ischemia. Moreover, such difference was more marked in the essential oil treated groups compared to the ischemia group while it was highly marked in the group treated with $50 \mathrm{mg} / \mathrm{kg}$ of the essential oil. This finding represents that passive avoidance memory enhanced in the essential oil-treated groups.

Linalool, one of the main compounds of C. aurantium essential oil, has anti-oxidant and anti-inflammatory properties. It was reported that linalool helped enhance memory and learning through decreasing the levels of inflammatory factors such as P38MAPK, NOS2, COX2, and IL-1 $\beta$ and increase in glutathione synthetase, INOS, COX-2, and P38MAPK (Sabogal-Guaqueta et al., 2016). Another study demonstrated that linalool could exert anti-inflammatory and anti-ischemic properties through inhibiting lipid peroxidation and free radicals (Park et al., 2016). Besides that, linalool inhibits production of chemokine mcp-1 which occurs during ischemia. Linalool prevents accumulation of the inflammatory cells in the brain through affecting mcp-1.

Borneol is another main compound of C. aurantium essential oil that is a bicyclic organic compound and a terpene, and can be found in many species. This compound can easily pass through the blood-brain barrier and help absorb many compounds from the blood-brain barrier. Liu et al. (2011) study indicated that borneol caused return of oxygen and glucose to reach normal condition during reperfusion nerve injury -induced and inhibition of ROS. In addition, it increases the expression of the induced activity of nitric oxide synthase and inhibits caspase 2, released factors in inflammation, and ІкBa (Liu et al., 2011). Sayed et al. study demonstrated that the level of TNF-a, that is an inflammatory factor, decreased after administration with thymol and carvacrol. Thymol and carvacrol exert anti-inflammatory effect via suppressing TNF-a and display antiapoptotic property via decreasing caspase 3 activity (El-Sayed et al., 2015).

The results of data analysis demonstrated that antioxidant property of the essential oil declined with increase in its dose. Regarding the available evidence, this finding can be explained by production of ROS following increasing the dose of anti-oxidant compounds to a specific level, which leads to decrease in anti-oxidant properties of these compounds and therefore decline in useful behavioral effects due to anti -oxidant property (Asgary et al., 2011).

\section{Conclusion}

C. aurantium essential oil due to anti-oxidant compounds has protective effects on spatial memory and passive avoidance learning during ischemia/ 
reperfusion. Hence, it might be beneficial to decrease the symptoms of ischemic patients.

\section{Ethical Issue}

The investigation conformed to the Guide for the Care and Use of Laboratory Animal, according to the ethical guidelines of IR SKUMS Bioethics Committee (Rec.2015.148).

\section{Conflict of Interest}

The authors declare no conflict of interest.

\section{Acknowledgement}

This work was supported by grant No. 1946 from Shahrekord University of Medical Sciences. The authors thank the Research Council of Shahrekord University of Medical Sciences and Shahrekord University, Iran for all supports provided.

\section{References}

Aazami MH. Metoprolol reduces the coronary collateral flow index: Alternative explanations. Coronary Artery Dis. 2004; 25: 508-13.

Adams HP, Bendixen BH, Kappelle LJ, Biller J, Love BB, Gordon DL, Marsh ER. Classification of subtype of acute ischemic stroke, Definitions for use in a multicenter clinical trial. TOAST. Trial of Org 10172 in Acute Stroke Treatment. Stroke 1993; 24: 35-41.

Adams RP, Sparkman OD. Review of identification of essential oil components by gas chromatography/mass spectrometry. J Am Soc Mass Spectrom. 2007; 18: 803-06.

Aminzadeh M, Amiri F, Abadi EA, Mahdevi K, Fadai S. Factors affecting on essential chemical composition of Thymus kotschyanus in iran. World Appl Sci J. 2010; 8: 847-56.

Asgary S, Moshtaghian S, Setorki M, Kazemi S, Rafieiankopaei M, Adelnia A, Shamsi F. Hypoglycaemic and hypolipidemic effects of pumpkin (Cucurbita pepo L.) on alloxaninduced diabetic rats. Afr J Pharm. 2011; 5: 2620-26.

Bakhtiaria E, Hosseini A, Mousavi SH. The role of ROS and NF $-\mathrm{kB}$ pathway in olmesartan induced-toxicity in HeLa and mcf-7 cell lines. Biomed Pharmacother. 2017; 93: 429-34.

Benzie IFF, Strain JJ, Lester P. Ferric reducing/anti-oxidant power assay: Direct measure of total anti-oxidant activity of biological fluids and modified version for simultaneous measurement of total anti-oxidant power and ascorbic acid concentration. Method Enzymol. 1999; 299: 15-27.

Bir LS, Demir S, Rota S, Koseoglu M. Increased serum malondialdehyde levels in chronic stage of ischemic stroke. Tohoku J Exp Med. 2006; 208: 33-39.

Chutia M, Deka-Bhuyan P, Pathak MG, Sarma TC, Boruah P. Antifungal activity and chemical composition of citrus reticulata Blanco essential oil against phytopathogens from North East India. LWT- Food Sci Technol. 2008; 42: 777-80.

El-Sayed EM, Abd-Allah AR, Mansour AM, El-Arabey AA. Thymol and carvacrol prevent cisplatin-induced nephrotoxicity by abrogation of oxidative stress, inflammation, and apoptosis in rats. J Biochem Mol Toxicol. 2015; 29: 165-72.

Espina L, Somolions M, Loran S, Conchello P, Garcia D, Pagan R. Chemical composition of commercial citrus fruit essential oils and evaluation of their antimicrobial activity acting alone or in combined processes. Food Control. 2010; 22: 896902.

Faraji F, Ranjbar A, Eshrati B, Talaie A, Shafie N, Pirasteh S. Comparing the oxidative stress indexes of CVA patients with control group. Arak Med Univ J. 2008; 11: 109-16.

Hadjinikolaou L, Kotidis K, Galinanes M. Relationship between reduced elasticity of extracardiac vessels and left main stem coronary artery disease. Eur Heart J. 2004; 25: 50813.

Hosseinzadeh S, Dabidi Roshan V, Pourasghar M. Effects of intermittent aerobic training on passive avoidance test (shuttle box) and stress markers in the dorsal hippocampus of Wistar rats exposed to administration of homocysteine. Iran J Psychiatry Behav Sci. 2013; 7: 37-44.

Hosni K, Zahed N, Chrif R, Abid I, Medfei W, Kallel M, Brahim NB, Sebei H. Composition of peel essential oils from four selected Tunisian Citrus species Evidence for the genotypic influence. Food Chem. 2010; 123: 1098-104.

Hossmann KA. Viability thresholds and the penumbra of focal ischemia. Ann Neurol. 1994; 36: 557-65.

Hritcu L, Ionita R, Motei DE, Babii C, Stefan M, Mihasan M. Nicotine versus 6-hydroxy-L-nicotine against chlorisondamine induced memory impairment and oxidative stress in the rat hippocampus. Biomed Pharmacother. 2017; 86: 10208 .

Huang YT, Wang GF, Chen CF, Chen CC, Hong CY, Yang MC. Fructus aurantii reduced portal pressure in portal hypertensive rats. Life Sci. 1995; 57: 2011-20.

Jamshidi-Kia F, Lorigooini Z, Amini-Khoei H. Medicinal plants: Past history and future perspective. J Herbmed Pharmacol. 2018; 1: 1-7.

Karatas F, Karatepe M, Baysar A. Determination of free malondialdehyde in human serum by high-performance liquid chromatography. Anal Biochem. 2002; 311: 176-79.

Khalili M, Roghani M, Ekhlasi M. The effect of aqueous Crocus sativus L. extract on intracerebroventricular streptozotocininduced cognitive deficits in rat: A behavioral analysis. Iran J Pharm Res. 2009; 8: 185-91.

Liu R, Zhang L, Lan X, Li L, Zhang TT, Sun JH, Du GH. Protection by borneol on cortical neurons against oxygenglucose deprivation/reperfusion: Involvement of anti-oxidation and anti-inflammation through nuclear transcription factor карpaB signaling pathway. Neuroscience 2011; 176: 408-19.

Mahmoudi M, Shamsi-Meymandi M, Foroumadi A, Raftari S, Asadi-Shekari M. Antidepressant effect of sour orange flowers extract on lipopolysaccharide-induced depressive- 
like behaviors in rat. J Kerman Univ Med Sci. 2005; 12: 24451.

Meeran MFN, Jagadeesh GS, Selvaraj P. Thymol attenuates inflammation in isoproterenol induced myocardial infarcted rats by inhibiting the release of lysosomal enzymes and downregulating the expressions of proinflammatory cytokines. Eur J Pharmacol. 2015; 754: 153-61.

Meilandt WJ, Barea-Rodriguez E, Harvey SA, Martinez JL. Role of hippocampal CA3 $\mu$-opioid receptors in spatial learning and memory. J Neurosci. 2004; 24: 2953-62.

Nakai A, Oya A, Kobe H, Kobe H, Yokota A, Koshino T, Araki T. Changes in maternal lipid peroxidation levels and antioxidant enzymatic activities before and after delivery. J Nippon Med Sch. 2000; 67: 434-39.

Niki E, Noguchi N, Tsuchihashi H, Gotoh N. Interaction among vitamin $\mathrm{C}$, vitamin $\mathrm{E}$, and beta-carotene. Am J Clin Nutr. 1995; 62: 1322S-26S.

Nussmeier NA. A review of risk factors for adverse neurologic outcome after cardiac surgery. J Extra Corpor Technol. 2002; 34: 10-14.

Park H, Seol GH, Ryu S, Choi IY. Neuroprotective effects of $(-)$ -linalool against oxygen-glucose deprivation-induced neuro- nal injury. Arch Pharm Res. 2016; 39: 555-64.

Pham-Huy LA, He H, Pham-Huy C. Free radicals, antioxidants in disease and health. Int J Biomed Sci. 2008; 4: 8996.

Pourmorad F, Hosseinimehr S, Shahabimajd N. Anti-oxidant activity, phenol and flavonoid contents of some selected Iranian medicinal plants. Afr J Biotechnol. 2006; 5: 1142-45.

Quervain D, Dominique JF, Roozendaal B, McGaugh JL. Stress and glucocorticoids impair retrieval of long-term spatial memory. Nature 1998; 394: 787-90.

Sabogal-Guaqueta AM, Osorio E, Cardona-Gomez GP. Linalool reverses neuropathological and behavioral impairments in old triple transgenic Alzheimer's mice. Neuropharmacology 2016; 102: 111-20.

Suo L, Kang K, Wang X, Cao Y, Zhao H, Sun X, Tong L, Zhang F. Carvacrol alleviates ischemia reperfusion injury by regulating the PI3K-Akt pathway in rats. PloS One. 2014; 9: e104043.

Wells PG, Mccallum GP, Lam KC, Henderson JT, Ondovcik SL. Oxidative DNA damage and repair in teratogenesis and neurodevelopmental deficits. Birth Defects Res C Embryo Today. 2010; 90: 103-09. 